\title{
Inimohver eesti eelkristlikus usundis
}

Tõnno Jonuks

Dómald võttis pärandi oma isa Vísburrijärelt ja valitses maad. Tema päevil oli Rootsis ikaldus ja nälg. Siis tõid rootslased suuri ohvreid Uppsalas. Esimesel sügisel ohverdasid nad kariloomi, aga nälg kestis edasi. Aga teisel sügisel oli neil inimohver, ent puudus oli nii nagu enne, kui mitte hullem. Aga kolmandal sügisel kogunes palju rootslasi Uppsalasse, kus pidi ohvritalitus olema. Siis oli juhtidel nõupidamine ja seal otsustati, et hädas on sü̈̈di Dómald, nende kuningas, ja ka see, et nad pidid ta ohverdama viljakusele ja ründama teda ja tapma ja määrima tema verega altari ja nii nad tegid. Nii ütleb Pjóðólfr:

On ennegi juhtunud nii, et vaenlase relv löönud kroonitud pea, kus lahingupaik oli punaporine verisest vihmast. Aga Dómald suri veristest kätest, ei tõusnud need vaenlaselt lahingukäras tõusid Rootsi alamatelt, et tuua onne maale.

Ynglinga saaga XV

\section{Inimohver üldiselt}

Eesti muinasusundi uurijad on seni inimohvri temaatikat vaid põgusalt puudutanud. Peaaegu kõikides käsitlustes on inimohvrit kui paganliku usundi tähtsaimat rituaali küll mainitud, kuid tavaliselt on piirdutud vaid üksikute illustreerivate tekstilõikudega. Põhjalikumalt aga inimohvrit siiani käsitletud ei ole. Ära tuleks kindlasti märkida Aliis Moora artikkel Eestlaste muistsest usundist kogumikus Religiooni ja ateismi ajaloost Eestis (Moora 1956), mille järgi ohverdati enamasti vaenlasi ja sõjavange ning ohvritoomise põhju-sena tuuakse välja viljaikalduse leevendamine Liivimaa Henriku kroonika I: 10 ning XXVI: 7 põhjal (Moora 1956: 25). Ka 
Skandinaavia usundi uurijad on enamasti piirdunud inimohvri käsitlemisega ülduurimuste sees. Üks põhjalikumaid leidub Jan de Vriesi monograafias Altgermanische Religionsgeschichte I-II (de Vries 1970).

Käesolev artikkel põhineb peamiselt kahel keskaegsel kroonikal: Henriku Liivimaa kroonika ja Bremeni Adami kirjutatud Gesta Hammaburgensis ecclesiae pontificium. Artikli materjalist on teadlikult kõrvale jäetud rahvaluuleline aines, mille peamiselt lasteohverdamisega seotud lugude võrdlus keskaegse materjaliga jääb edaspidiseks uurimisteemaks.

\section{Inimohver Eesti arheoloogilises materjalis}

Arheoloogilises materjalis on inimohvri eristamine küllaltki keeruline ja problemaatiline. Esiteks kindlasti sellepärast, et inimesi on ohverdatud vähe. Teiseks sellepärast, et Eestis on siiani arheoloogiliselt uuritud vaid üksikuid kultuspaiku, kust üldse võiks leida jälgi inimese ohverdamisest. Kolmandaks puuduvad meil täpsed teadmised, kuidas eristada ohverdatud inimest mingisse traumasse surnust. Siiani on teada vaid üksikud luud või matused, mis tunduvad viitavat inimohvrile. Nii on Lagedi III kivikirstkalme kirstust leitud koos lapse luustikuga täiskasvanu lõualuu, mis Valter Langi hinnangul võib viidata rituaalsele kannibalismile (Lang 1996: 213). Kaks viidet inimohvrile on pärit ka Tõugu kivikalmetest, kus perioodist 500-200 aastat eKr pärineva tarandi põhjakirdenurgast tarandikivide alt leiti täiskasvanu koljutükke koos mõne loomaluuga (Lang 2000: 111). Samuti leiti ajavahemikust 200 a eKr-50 a pKr pärit üksiktarandkalme põhjakirdepoolse nurgakivi alt vastsündinu kolju, mida samuti võib tõlgendada inimohvrina (samas: 105). Tõenäoliselt assotsieerub inimohvri või millegi sellelaadsega ka skalpeerimisjälgedega 6-8-aastase poisi kolju Tõugu IIC: 3 kalmest (samas: 111) ning matused kivikalmetest, kus keha ja pea on maetud või käsitletud eraldi.

Seega on seni kõik Eestis teadaolevad arvatavad inimohvriga seonduvad leiud pärit Põhja-Eestist, eelkõige Virumaalt. Vaevalt see tähendab, et vaid seal on inimesi ohverdatud, pigem on see seotud probleemiga, millele juhib tähelepanu ka Valter Lang (Lang 2000: 106), et kivikalmete kaevamisel ei ole alati eemaldatud tarandimüüri kive ja seetõttu on võinud ka seal all asuvad matused 
tähelepanuta jääda. Vägagi tõenäoline on ka, et inimeste ohverdamine ongi olnud marginaalne nähtus ja sellest ei olegi saanud jääda kuigi palju jälgi (Lang 2000: 211). Samas on aga sellisel juhul tähelepanuväärne nende suur kontsentratsioon Tõugu tarandkalme kuues tarandis.

Seega on veel vara püstitada hüpoteese kivikalmetega seonduvate tõenäoliste inimohvrite leviku, arvukuse ja tähenduse kohta. Kuna ohvrid on leitud tarandkalme müüride alt, on nad sinna paigutatud enne kalme ehitamist ning tõenäoliselt ongi need seotud eelkõige kivikalme kui rituaalse koha kasutuselevõtuga. Et kivikalmete puhul nende rituaalne tähendus võib olla suurem kui tähendus matmiskohana, on oletatud mitmel pool (Lang 2000: 213; Kaliff 1997). Arheoloogiline materjal jätab aga lahtiseks küsimused nii ohvri toomise, tema surmamise kui ka muude seonduvate rituaalide kohta, milleks tuleb oodata lisauurimisi.

\section{Keskaegsed kroonikad Eesti inimohvrist}

Eesti viimaste eelkristlike sajandite inimohvrite kohta on varakeskaegsetest kroonikatest mõnevõrra rohkem andmeid. Ehkki mitmetes käsitlustes on neid arvukalt kasutatud, nimetaksin neid siinkohal uuesti. Neist üks huvitavamaid on Bremeni Adami 11. sajandi lõpul kirja pandud Gesta Hammaburgensis ecclesiae pontificium (Andmed Hamburgi kirikuvürstidest). Tänu selle arvukatele geograafilistele ja etnograafilistele kõrvalepõigetele on tegu ühe keskaja väärtuslikema kroonikaga. Teose kirjutamisel on autor kasutanud arvukalt nii keskaegseid arhiiviandmeid, aga ka oma kaasaegsete suulisi kirjeldusi. Adam ise arvatavasti kirjeldatud maades ei käinud ja seetõttu võib mõnigi tema kirjeldus olla küsitav.

Inimese ohverdamist tunneb Adam peaaegu kõikidelt maadelt ida pool Läänemerd. Nii on Adami andmetel Kuramaa suur saar, kus elavad ebajumala kummardamise tõttu eriti verejanulised inimesed, kellest on parem eemale hoida (XVI ptk). Järgmises peatükis kirjeldatakse teist saart, mille nimi on Aestland (Eesti) ning mille elanikud samuti ei usu kristlaste jumalat. Selle asemel austavad nad draakoneid ja linde (dracones adorant cum volucribus), kellele nad ohverdavad kaupmeestelt ostetud inimesi. Neid vaadatakse enne hoolikalt, et nad oleksid terved ja et draakon ohvrit tagasi ei lükkaks (XVII ptk). 
Kõige tihedamalt esineb inimohvrit ootuspäraselt Henriku Liivimaa kroonikas. Otseselt inimohvrist on juttu seoses preestritega, kelle ohverdamisest räägitakse peatükkides I: 10 ja XXVI: 7 . Tähelepanuväärne on ka peatükis I: $10 \mathrm{olev}$ liisuheitmise kirjeldus, kus kristlaste jumal istuvat liisuhobuse seljal ja sundivat seda otsus-tama kristlaste kasuks. Alles pärast jumala mahapühkimist hobu-se seljalt saab loom langetada õige otsuse.

Inimesi võidi Henriku teadetel mõnikord ohvrdada ka üsna arvukalt. Näiteks peatükis IX: 12 öeldakse:

[---] liivlased tapsid neist (ristisõdijaist) seitseteist, kellest nad mõned tõid ohvriks oma jumalalile, tappes nad julma piinamisega.

Piinarikas surm kaasneb inimeste ohverdamisega üsna tihti ja paljude rahvaste juures. See annab võimaluse tõlgendada ohvrina teisigi surnuks piinatud inimesi. Näiteks pärast Ümera lahingut, kus

[---] eestlased olid võtnud kinni sakslasi, liivlasi ja lätlasi ning mõned neist lihtsalt tapnud, teised praadinud elusalt ja mõned kiskunud riietest paljaks ja teinud nende selja peale mõõkadega risti ning lõiganud pärast kõrid maha (XIV: 8).

Risti lõikamine seljale tuletab meelde Skandinaavia saagade kuulsat verekulli lõikamist (blóðörn rísta).

\section{Arutelu}

Edaspidi käsitletakse vaid kirjalikest allikatest teadaolevaid inimohvri toomise juhtusid ning arheoloogiline materjal jäetakse välja, sest neid kahte lahutava aastatuhande jooksul on Eesti muinasusundis leidnud tõenäoliselt aset üsna suured muutused. (See hõlmab eeskätt tarandkalmete mahajätmist ja ilma konstruktsioonideta kalmete kasutuselevõttu 5.-6. sajandil pKr, mistõttu kultuslik tegevus kandus tõenäoliselt teistesse kohtadesse (hiiepaigad, pealike talud jmt). Seega ei saa neid kaht allikat prae-guste andmete põhjal võrrelda.)

Eesti muinasaja lõpusajanditel toodud inimohvrid on ilmselt olnud eelkõige erakorralised ja kindlasti mitte regulaarsed. Järeli- 
kult on inimohvrit toodud eelkõige erakorralistel põhjustel. Rahu ajal võib selleks olla nälg, ikaldus, ulatuslik taud vmt. Kroonikate andmetel tundub, et ohverdati orje, keda osteti kaupmeestelt. Samas on tõenäoline, et ohvriks kõlbasid ka tavalised orjad, keda ei pidanud spetsiaalselt ohverdamiseks ostma. Henriku Liivimaa kroonikast on teada, et inimohvreid toodi eriti sõja ajal, mil ohvriks kõlbasid nii sõjavangid kui ka ristiusu preestrid. Preestritel kui usulistel juhtidel usuti tõenäoliselt olevat suurem vägi ja seetõttu peeti ka ohvrit mõjusamaks. Sõjavangide ohverdamine oli üldine nähtus kogu Põhja-Euroopas (Turville-Petre 1975: 252; de Vries 1970 II: 408). Skandinaaviast on teada, et ohvriks kasutati ka kurjategijaid ja surmanuhtlusel oli sakraalne tähendus (Turville-Petre 1975: 254; vt lähemalt Ström 1942).

Ehkki vaid Bremeni Adami kroonikast on teada, et ohvriks toodav inimene pidi olema füüsiliselt terve, on tõenäoline, et selline nõue on üldisem. Füüsiline täiuslikkus on olnud tähtis ja ka määrav mitte ainult ohvrite, vaid ka kuningate ja preestrite valimisel (vt lähemalt Frazer 2001).

\section{Inimohvri toomise põhjused ja ohvri saaja}

Kroonikate andmetel tundub, et inimohvri toomise peamiseks rahuaegseks põhjuseks on arvatavasti olnud viljakuse ja seeläbi elu jätkamise soodustamine.

Ülaltoodud tekstilõikudes on vaid ühes mainitud kultusobjekte - draakonit ja lindu. Ka on tekstis vihjatud, nagu oleks ohver mõeldud vaid draakonile. Draakon mütoloogilise objektina on kogu Põhja-Euroopas üsna harv nähtus. Paar korda on teda mainitud Skandinaavia saagades (neist üks kord ka seoses Eestiga, kui islandlane Porkell Hákur ehk Ärpleja kohtab Aðalsýslas ehk Eestis lenddraakonit ning tapab ta (Alas 2001: 221)). Samas esineb draakonit üsna tihti keskaegsetes kroonikates, Bremeni Adamil küll vähe, kuid see-eest on Saxo Grammaticus draakonist rääkinud üsna palju. Igal juhul võib draakoni siduda hoopis skandinaavlaste ja ka lääneeurooplaste ettekujutusega Eestist (aga ka Kuramaast ja Lätist, eriti aga Soomest) kui paganlikust, seega ka võõrast, kummalisest ja ohtlikust maast). Kui Bremeni Adami kirjeldusest üldse tõetera otsida, siis võis ohvrisaajaks olla hoopis madu, kes kas rändajate jutus või krooniku sule all draakoniks moondus. 


\section{Tõnno Jonuks}

Madu on aga meie kultuuriruumis üsna tuntud tegelane, kellega tavaliselt seonduvad just viljakuseteemalised müüdid. Ka on kõik, mida madu sümboliseerib, seotud ühel või teisel viisil viljakusega (maa, vesi ja vihm, kolle) ning madu on levinud kujutis mitte ainult Eestis alates kiviajast (Jaanits1961: 22) kuni kesk-ja uusaegse rahvausundini välja.

Pean ülaltoodud tekstilõiku tähtsaks veel seetõttu, et tegemist on ainukese rahuaegse kirjeldusega inimese ohver-damisest ja Henriku Liivimaa kroonikast pärit märkmetel on hoopis teine kontekst.

Henriku kroonikas ei ole ohvrisaajaks enam draakon ega lind, vaid ohver tuuakse oma jumalaile (diis suis). Kroonikas on jumalate tähenduses kasutanud üldse vaid kaht terminit - anima ja deus. Kui animat (hinge) on kasutatud üksnes paganlike ehk kohalike jumalate kohta (aga ka kristlaste hingede märkimaks), siis deusi on kroonik kasutanud nii kristlaste jumala kui ka kohalike jumalate kohta. Oletada võib, et animaga tähistatakse vaime ja muid üleloomulikke olevusi (kaitsehaldjaid), deusega aga jumalat. Ehkki nende vahe ei ole lõplikult selge, võib arvata, et paganlikus usundis on kroonik kirjeldanud vastavalt madalamaid ja kõrgemaid olendeid ning inimohver oli mõeldud mõnele panteoni kõrgemale jumalale.

Teise erinevusena tuleks välja tuua, et ohverdatav ei ole ori, vaid sõjavang. Seegi osundab, et ohvritoomise põhjuseks oli tõenäoliselt sõjaõnne tagamine. Ehkki me ei tea midagi eesti muistsest panteonist ega sealsetest sõjajumalatest, kellele selline ohver pidi olema määratud, on ainsa oletatava eesti jumala Tharaphita nime püütud seostada ka sõjajumalaga (vt lähemalt Viires 1990).

Võiduka lahingu järgsele klassikalisele tänuohvrile näib viitavat kirjeldus Liivimaa Henriku kroonikast (XXVI: 7), kuidas tartlased pärast kõikide sakslaste tapmist ja nende vara jagamist küsivad oma jumalatelt (deorum suorum), kas need soovivad ohvriks härga või preestrit. Ka E. O. G Turville-Petre toob Skandinaavia peamise inimohvri toomise põhjusena välja just lahingujärgse tänuohvri (Turville-Petre 1975: 252). See aga, et tartlased tahtsid tänuks sakslaste üle saadud võidu eest ohverdada sümbolina preestrit, näitab omakorda religiooni rolli muistses vabadusvõitluses.

Kogu sõjakas kontekstis leiame siiski ka Henriku kroonikast ühe inimohvri toomise kirjelduse, kus ohver tuuakse ikalduse lõpe- 
tamiseks ja nälja leevenduseks. Peatükis I: 10 kirjeldab kroonik liivlasi, kelle põldudelt on saak liigvihmade tõttu hävinud, kuid tsistertslaste venna Theoderici põldudel on vili andnud rikkaliku saagi. Seejärel koguneb rahvas, kes hobuse abil küsib jumalatelt nõu venna ohverdamise kohta. Seda kirjeldust on ka Aliis Moora seostatud viljakuskultusega (Moora 1956: 25).

\section{Ohvritooja}

Kuna teada on, et inimohvrit peeti usundi tähtsaimaks ohvriks, mida toodi vaid erakorralistel juhtudel, siis on tähtis küsimuseks ka see, kes tappis ohverdatava inimese. Nagu mujalgi Põhjalas, on ka Eesti uurijad seisukohal, et erilist, spetsialiseerunud preestrite klassi Eestis ei ole olnud. Ohvrit on toonud kas perepead või suuremate ohverdamiste puhul kihelkonna või maakonna vanemad (Loorits 1932: 160). Oma roll oli ka nõidadel, tarkadel ja arbujatel, kelle põhiülesanne oli siiski ennustamine ja ravitsemine. Peaaegu sama pilt tekib siis, kui vaadata siinesitatud lõike inimohvrite kohta. Tavaliselt on öeldud vaid, et toodi ohvriks. Henrik on vaid ühel kohal (I: 10) maininud ohvritalituse läbiviijat - arbujat (ariolus) , kelle ülesanne piirdub jumalate tahtmisel vaid ennustamisega. Peaaegu identne lugu on teada Araabia teadlaselt Ibn Rustah'lt, kes kirjeldab Skandinaavlaste inimohvrit 10. sajandil Venemaal. Ka seal pidi tark või preester otsustama kõigepealt (muidugi jumalatelt nõu küsides), kas ohverdatakse mees, naine või loom (Turville-Petre 1975: 253). Mõnevõrra rohkem on preestritest teada Bremeni Adami Kuramaa kirjeldusest 16. peatükis, kus öeldakse:

Kuramaal on kõik majad täis ennustajaid (divinis), ettekuulutajaid (auguribus) ja surnutemanajaid (nigromanticis) [---].

Otseselt kultustalitust läbi viivat preestrit ei ole aga siingi mainitud. Seega võib nentida, et nii nagu teiste ohvrite puhul, tõi ka inimohvri tõenäoliselt pealik või vanem. Samas ennustamine (mille alla mahuvad kõik Adami välja toodud ametid) ja sellest arusaamine, mis nõudis spetsiaalseid oskusi, võis olla pigem arbujate ja tarkade pärusmaa. 


\section{Inimohvri toomise viisist}

Peaaegu kõikjal, kus on juttu inimohvrist, on läbivaks teemaks valu ja piin ning on öeldud, et ohvrid tapeti julma piinamisega. Piinarikas surm ja valu on läbivad teemad mitte ainult Põhja-Euroopas, vaid enam-vähem kõikjal maailmas, kus on inimohvrit toodud. Seega võib pidada seda universaalseks nähtuseks.

Julm piinamine, mis inimohvri toomisel kõikjal tooni annab, võib viidata inimohvrile ka kohtades, kus seda ei ole otseselt nimetatud. Henriku Liivimaa kroonika peatükis XXVI: 6 on juttu sellest, kuidas koos foogt Hebbega piinati surnuks ja rebiti sisi-konnad lõhki veel paljudel taanlastel. Peatükis XIV: 8 kirjeldab Henrik, kuidas eestlased pärast võidukat Ümera lahingut võtsid vangi neliteist vastast, kellest osa praeti elusalt, osale aga lõigati mõõkadega seljale risti ja seejärel kõri maha. Kroonik avaldab sealjuures veel lootust, et nad kõik märtritena ka taevasse jõudsid. Seljale risti lõikamine sarnaneb Skandinaavia saagadest tuntud verekulliga (blóðörn), kus ohvri selg lõigati lahti, keerati ribid kõrvale ja rebiti kopsud välja, nii et ohver lämbus õhupuudusesse. Nii on öeldud ka Vanema Edda laulu Sigvördrist Fafniritapjast II. peatüki 26. stroofis:

Nüüd veritsev kotkas on välkuva mõõgaga

Sigmundri tapjale seljale kriibatud.

Skandinaavias oli see ohver pühendatud jumal Odinile, kuid kombe enda tagamaad on siiani selgusetud. On arvatud, et sellist ohvrit tegelikkuses ei olegi toodud (Turville-Petre, 1975: 255). Saagade järgi olevat verekulli kasutanud eriti need, kes maksid kätte isa eest (Turville-Petre, 1975: 255).

Germaanlaste ja keltide juures on teada, et kuna inimohver ei olnud mõeldud ainult ühele jumalale, tuli erinevatele jumalatele ohverdatud inimesed ka erinevalt hukata. Kõige levi-numaks viisiks oli poomine või kägistamine, mida üldjuhul seostatakse Odinile ohverdamisega, kes ise oli samuti "poodud jumal" (Turville-Petre 1975: 253-254). Ohver võidi visata alla kaljult (Freyrile), lõhkuda ohvri selgroog (Thorile) või ta uputada (näiteks Nerthusele) (Turville-Petre 1975: 254). 


\section{Inimohvri arvust}

Rahuaegse ohvri puhul on kõige tõenäolisem kõneleda ühest ohverdatavast inimesest. Muistse Skandinaavia kuulsaimast templist Vana-Uppsalas on küll teada, et iga üheksa aasta järel ohverdati seal üheksa päeva jooksul üheksa elusolendit, inimene kaasa arvatud (de Vries 1970 II: 420). Tõenäoliselt Eesti puhul nii suurejoonelisest ohvrist rääkida ei saa, ehkki Bremeni Adami hoiatus eestlastest kui verejanulistest inimestest, kellest on parem eemale hoida, võiks selleks põhjust anda. Tõenäolisem on, et kroonik on sellise märkuse lisanud seetõttu, et tegemist oli ristimata ja seega barbaarse rahvaga. Eduka lahingu järel toodud ohvrite hulk sõltus aga eelkõige vangide arvust.

\section{Kokkuvõtteks}

Tuleb tõdeda, et inimohver on olnud Eestis tuntud juba alates metalliaja algusest. Neist varaseimate põhjuseks oli meie praeguste andmete kohaselt kalme kui rituaalse paiga pühitsemine. Kirjalikest allikatest teadaolevate ohvrite põhjused võib aga laias laastus jagada kaheks: 1) nälja, ikalduse ja tõenäoliselt ka suuremate epideemiate puhul, kui eesmärgiks oli lepitada jumalaid ja taastada elamisväärne keskkond, ja 2) eduka lahingu järgne tänuohver. Kuna antud järeldused on tehtud nappide kroonikateadete põhjal, võib neile lisada ka muudel ekstreemsematel juhtudel toodud ohvrid.

Inimohvri toomine on kindlasti olnud kollektiivne sündmus, nagu teistegi usundite puhul, ning ohvritoomise juures etendasid tõenäoliselt suurt rolli targad, kes pidid ennustustest välja lugema, keda ohverdada. Ohvri enda on aga toonud tõenäoliselt kohalikud vanemad või pealikud, kes sümboliseerisid kogu kollektiivi.

Ohvriliik, kus ohverdati sõjavange, on kindlasti olnud julm ja sellega on kaasnenud piinarikas surm. Võimalik, et see iseloomustas ka rahuaegset viljakusohvrit. Kroonikaist tuntud väljend "julm piinamine" võib aga kristlasest kroonikakirjutaja puhul, kes oli pealegi paganate suhtes vaenulikult meelestatud ja pidi näitama nende primitiivseid kombeid, käia kõikvõimalike hukkamisviiside kohta. Lõplikult ei saa välistada ka võimalust, et kroonikateated 
inimeste ohverdamise kohta ongi suuresti fabritseerinud kristlikud kroonikud, kellel oli "ülesanne" näidata paganlikke ja ristimata maid metsikute ja barbaarsetena.

\section{Kirjandus}

Bjarni Aðalbjarnarson 1979. Snorri Sturluson. Hemskringla I. Islenzk fornrit XXVI bindi. Réykjavík.

Henriku Liivimaa kroonika 1993. Richard Kleis (tõlk). Tallinn.

Frazer, James 2001. Kuldne oks. Triinu Pakk (tõlk). Tallinn.

Jaanits, Lembit 1961. Jooni kiviaja uskumustest Eestis. Religiooni ja ateismi ajaloost Eestis.

Kaliff, Anders 1997. Grav och kultplats: eskatologiska färeställningar under yngre bronsålder och äldre järnålder i Öste. Aun. Uppsala.

Lang, Valter 1996. Muistne Rävala. Muinasaja teadus 4. Tallinn.

Libe, Juhan \& Oinas, August \& Sepp, Hendrik \& Vasar, Juhan 19321933. Eesti rahva ajalugu. Tartu.

Loorits, Oskar 1932. Eesti rahvausundi maailmavaade. Tartu.

Moora, Aliis 1956. Eestlaste muistsest usundist. Religiooni ja ateismi ajaloost Eestis I. Tallinn.

Ström, Folke 1942. On the Sacral Origin of the Germanic Death Penalties. Stockholm.

Turville-Petre, Edward Oswald Gabriel 1975. Myth and Religion of the North. New York.

Vanem Edda 1974. Rein Sepp (tõlk). Tallinn.

Viires, Ants 1990. Taara avita. Looming 10. Tallinn.

de Vries, Jan 1970. Altgermanische Religionsgeschichte I-II. Berlin. 